\title{
Contrato narcisista y proyecto identificatorio en la película Una vida mejor
}

\author{
Narcissistic contract and identificatory project in film A Better Life \\ Jesús Cisneros - Herrera a, \\ Denice Rodríguez - López, b, Martha Isabel Salinas - Salazar c, Gelacio Guzmán - Díaz d
}

\begin{abstract}
:
Narcissistic contract and identificatory project (1) are concepts applied to the crossroads that adolescents face in the transition from family to social world. Adolescents find possibilities of being, each one of which promise them certain things. Adolescents' choice is a narcissistic contract in as much as, by signing it, they assume a commitment with society or with a part of it. In exchange, adolescents expect their narcissism to be sustained by society. At the same time, a reconfiguration of identifications begins through which adolescents try to be part of a transgenerational chain than not necessarily is their family's, but a particular social groups', more or less broad, that they reproduce and perpetuate. This process is portrayed in the film A better life (2). In this paper, the film's story is analyzed using psychoanalytical concept aforementioned.
\end{abstract}

Keywords:

Narcissistic contract, identificatory project, adolescence, migration

Resumen:

El contrato narcisista y el proyecto identificatorio (1) son conceptos que se aplican a la encrucijada que enfrenta el adolescente en la transición de la familia al plano social. El adolescente encuentra posibilidades de ser, cada una de las cuales promete ciertas cosas. La elección del adolescente es un contrato narcisista en tanto que al signarlo el adolescente asume un compromiso con la sociedad o con una sector de ella a cambio del cual espera el apuntalamiento social de su narcisismo. Al mismo tiempo, se inicia una reconfi guración de las identificaciones con la cual el adolescente se inserta en una cadena transgeneracional que no necesariamente es la de su familia, sino la que busca reproducir y perpetuar un grupo social más o menos amplio. Este proceso se ilustra en la película Una vida mejor (2). En el artículo se analiza la historia de la película con base en los conceptos psicoanalíticos antes mencionados.

Palabras Clave:

Contrato narcisista, proyecto identificatorio, adolescencia, migración

\section{Introducción}

Durante la adolescencia se presentan cambios importantes del orden psíquico del individuo debido a los cambios corporales, la inserción en el plano de lo social, la renegociación de la relación con los padres y la reconfiguración de las identificaciones. En esta etapa el adolescente signa un contrato narcisista y se plantea un proyecto identificatorio (1), operaciones que tienen lugar a nivel de la instancia yóica.
El origen del yo se remonta al encuentro entre el bebé y la madre. En las primeras experiencias del bebé, la boca $y$ el pecho forman una unidad; las huellas de las sensaciones derivadas del contacto con el pecho conforman el primer núcleo del espacio psíquico. Las sensaciones corporales y los objetos del mundo que se relacionan con ellas se representan en la psique como indisociables. El reconocimiento de la separación entre el bebé y la madre, es una experiencia dolorosa, pero inevitable (1).

a Autor de Correspondencia, Universidad Autónoma del Estado de Hidalgo, Escuela Superior Atotonilco de Tula, ORCID: 0000-0003-13708086, Email: jesus_cisneros@uaeh.edu.mx

๖ Universidad Autónoma del Estado de Hidalgo, Escuela Superior Atotonilco, Email: denicerolo@ gmail.com

๖ Universidad Autónoma del Estado de Hidalgo, Escuela Superior Atotonilco, Email: martha_1748@hotmail.com

Universidad Autónoma del Estado de Hidalgo, Escuela Superior Atotonilco, ORCID: 0000-0003-4869-8658, Email: gelacio_guzman@uaeh.edu.mx 
Para Freud, el mecanismo que origina al yo es la identificación primaria, que tiene lugar con la madre. Una imagen totalizante del bebé, con la cual aparece también el narcisismo. Esa imagen es investida con la libido que hasta entonces había tenido carácter autoerótico (3). Para Lacan, el yo surge durante el estadio del espejo, cuando el niño es capaz de reconocer su imagen como anticipación de la unificación de un cuerpo del que aún no se tiene dominio (4).

De acuerdo con Winnicott (5), la mirada de la madre es el primer espejo del bebé. En esa mirada y los gestos de la madre, el bebé reconoce el amor, la ternura, la indiferencia, el odio o todo aquello que él significa para ella. El niño intuye que él es el objeto de deseo de la madre, y él quiere ser ese objeto de deseo. Su experiencia es la de ser considerado maravilloso, lo más preciado, lo único para la madre. El yo se vive en ese momento como un yo ideal. El bebé desea ser el objeto de deseo de la madre, pero también desea lo que la madre desea, y también desea poseer sólo él a la madre. El deseo es deseo de otro (6).

Todos estos aspectos están involucrados en la formación del yo. Una vez constituido, el yo adquiere características particulares por medio de la identificación secundaria. El discurso parental acerca del propio niño, aporta numerosos elementos que moldean al yo. La forma en los padres lo perciben y hablan de él -de lo que es y de lo que esperan que sea- constituye la oferta simbólica a partir de la cual se configuran las identificaciones secundarias (1).

En el curso del desarrollo, el niño pierde el lugar privilegiado en la economía libidinal materna. Ella dirige su atención cada vez más hacia otros aspectos de su vida a medida que el niño adquiere crece y necesita menos cuidados. El yo se da cuenta que ya no es el yo ideal, por lo que se siente obligado a hacer cosas para ser otra vez el niño maravilloso que antes fue. Se esfuerza para lograr cosas que, supone, lo harán merecedor del amor y el reconocimiento de los padres. Para hacerlo se fija metas, las cuales constituyen el ideal del yo. Para que el sostén narcisista del yo se mantenga, debe alcanzar esas metas; eso lo hará sentirse orgulloso de sí mismo (6).

Las identificaciones con las que se cierra el ciclo de la sexualidad pregenital son las que introyectan los mandatos y prohibiciones paternas alrededor de los deseos edípicos. El niño renuncia a sus padres como objeto sexual y se constituye el superyó. Entre los 6 y los 12 años de edad, los intereses del niño se alejan de la sexualidad, lo cual permite que desarrolle habilidades.

En la pubertad, comienza la sexualidad genital y se revive la pregenital, que se integra a aquella. En consecuencia, los deseos edípicos resurgen, pero ahora resultan más amenazantes puesto que biológicamente el adolescente es apto para tener un encuentro genital con los objetos de su deseo. Por ello, el adolescente tiene que salir de su núcleo familiar para encontrar otros objetos de deseo y amor entre otros adolescente.

A partir de ese momento, el campo de lo social cobra mayor importancia en la vida del adolescente. La necesidad de salir de su familia lo impulsa a buscar un lugar en el grupo de amigos, la comunidad, la escuela y, finalmente, en la sociedad. Esta etapa es crucial en el desarrollo del individuo, pues la tarea de asimilar la sexualidad genital y los cambios corporales implica transformaciones profundas en el psiquismo, como la reconfiguración de las identificaciones secundarias y el contrato narcisista.

El contrato narcisista tiene que ver con el último factor que interviene en el modo en que los padres invisten a su hijo (1). Desde el principio, la relación de los padres con el hijo está permeada por la relación de ellos con su medio social. Ellos recuperan un segmento del discurso social acerca del niño, en el cual se anticipa lo que el niño será, al igual que en el discurso particular de los padres. Es decir, la sociedad crea lugares simbólicos a los cuales asigna a los niños, ya sea de acuerdo con su origen o sus características.

El adolescente es capaz de reconocer esos discursos, sociales y familiares, y de buscar en ellos referencias que le permitan proyectarse en el futuro, de modo que su alejamiento de la familia no implique sólo una pérdida, sino un cambio del soporte identificatorio. Sin embargo, cuando los padres en tanto pareja se encuentran en conflicto con su medio por alguna razón, el adolescente se representa como heredero del conflicto de los padres que lo hacen sentirse en un lugar de rechazo, exclusión, agresión u omnipotencia, por ejemplo, en relación con la sociedad.

Aulagnier (1) menciona que los grupos sociales poseen un discurso que comprende el conjunto de las voces presentes, por lo que lo llama simplemente el discurso del conjunto. Una parte de este discurso está formada por los enunciados fundamentales, es decir, aquellos cuyo objeto es el propio grupo, como es el caso de los enunciados míticos, sagrados o científicos. Para cumplir con su función, estos enunciados deben ser recibidos como certezas.

La relación del sujeto con el conjunto depende del grado de investidura de sus enunciados fundamentales. Integrarse al campo social implica que el sujeto se apropia de una serie de enunciados que repite. Esto le aporta la certeza de que existe un discurso en el que la verdad acerca del pasado está garantizada y confianza en la verdad acerca de las previsiones del futuro. Para el funcionamiento social, es necesario que el adolescente invista un modelo futuro. Si el sujeto pierde toda certeza acerca del origen, también pierde su pertenencia al grupo y sus perspectivas futuras. 
A cambio de su adherencia al discurso del conjunto, el grupo también inviste al sujeto y le transmite la idea de sujeto ideal, que es aquel que tiene el derecho a pertenecer al dicho grupo y confía en él la función de dar continuidad a su existencia. El pacto que se da entre el sujeto y el grupo implica que éste reconoce al sujeto como uno de sus integrantes y que el sujeto se compromete a repetir el fragmento de discurso del conjunto que le corresponda. En otras palabras, el conjunto se convierte en el soporte de una parte de su libido narcisista.

\section{Una vida mejor (Weitz (2011)}

Una vida mejor (2) cuenta la historia de una familia de origen mexicano en EUA, o lo que queda de ella, puesto que la madre se ha marchado. Carlos es un migrante mexicano que trabaja en California como jardinero, y vive junto con su hijo, Luis, de 14 años de edad. Al principio, no se explican las razones por las que la madre de Luis se haya ido. Carlos sale de casa muy temprano y regresa muy tarde, de modo que el tiempo que pasa con su hijo es mínimo, apenas para decirle que se duerma y que se despierte, preparar el desayuno y saber, de manera superficial, cómo va en la escuela. La actitud de Luis es hostil hacia Carlos, incluso despectiva. En la comunicación por parte del padre, predominan los mensajes del deber ser: estudia, trabaja, no faltes a la escuela, es importante la escuela, la escuela es todo. Más allá de eso, padre e hijo no comparten experiencias, sentimientos, ideas o historias de su propia familia.

Carlos vive con el miedo constante de ser descubierto por la policía de migración y ser deportado a México. Su patrón le ofrece venderle su camioneta y dejarle su cartera de clientes, pues ya piensa regresar a México. Sin embargo, el miedo a la deportación lo hace rechazar la oferta. Además, ha perdido mucho dinero al tratar de legalizar su estatus en EUA, pues el abogado que contrató lo estafó. Así que, a todo lo que aspira en lo inmediato es "ser invisible", que nadie lo vea, mientras el "sueño americano" que lo llevó a EUA deberá esperar su cumplimiento.

Carlos tolera su situación gracias a la esperanza de que el futuro de su hijo sea mejor. A pesar de su estatus de migrante ilegal, Carlos defiende el respeto a la ley, la honradez, el esfuerzo y la importancia de estudiar, y trata de transmitir esas ideas a Luis. Sin embargo, la fractura de su relación hace que Luis lo rechace a nivel afectivo y, por lo tanto, también rechaza su discurso. La otra alternativa que se le presenta a Luis en el espacio de socialización es por completo opuesta a la que plantea su padre. Luis es novio de la hermana de un pandillero y su amigo más cercano es un adolescente de su edad que, siendo hermano de otro pandillero que está en la cárcel, aspira a entrar en la pandilla.

A lo largo de la película, Luis oscila entre una y otra oferta simbólica para investir el espacio social (1), a punto de signar su contrato narcisista. En el plano posicional (7), el funcionamiento de esta familia es esquizo-paraniode: Luis se identifica con los aspectos malos y a su padre con lo bueno, pero lo bueno desvalorizado, despreciado, rechazado, como un intento de tener control omnipotente del padre. Lo malo resulta más valioso, porque se asocia con prestigio en las calles y entre los pandilleros, y más dinero. En una escena, en que Luis y su amigo se encuentran al hermano de su novia y le dicen que ya quieren iniciarse, lo ven cómo se aleja subiendo unas escaleras para reunirse con sus compañeros. La escena ilustra la admiración que despierta en el amigo de Luis esa vida. Luis no se muestra tan convencido de querer esa vida, pero no ve otra alternativa aparte de la que defiende su padre.

En cambio, lo que el discurso familiar defiende se asocia más con la pobreza y la humillación; el trabajo de jardinero resulta vergonzoso para Luis. La falta de esperanza de acceder a una vida mejor por pertenecer a su familia, hace a Luis estar resentido con la sociedad. Ese resentimiento es lo que lo iguala a los pandilleros y lo que puede llevarlo a unírseles. Si adopta el criterio de la clase social favorecida, su narcisismo quedaría muy mermado; en cambio, adoptando el de la pandilla, su narcisismo podría resultar fortalecido.

Carlos trata de ser estricto e imponer reglas, pero sin la firmeza y el tiempo suficientes, tal vez temeroso de descubrir qué pasa realmente por la mente de su hijo. Ante insinuaciones de Luis como "voy a asaltar a una anciana en la calle para conseguir dinero", Carlos trata de ser una figura de autoridad, pero sin que pueda asegurarse de que sus órdenes se cumplen.

En el plano económico del psiquismo (7), el sufrimiento está presente en ambos, pero cada uno busca tomar distancia de su dolor. En lo manifiesto, su situación económica es fuente de insatisfacción: el barrio en que viven y la escuela de Luis está llena de violencia, criminalidad y pandillerismo que amenazan con absorber la vida de Luis. Los dos se dan cuenta de eso, pero cada quien se lo reserva para sí mismo: la preocupación de Carlos y el enojo de Luis. En un nivel más profundo, hay un sufrimiento disociado por el abandono de la esposa y madre. En los momentos en que se habla de ella, Luis manifiesta su rechazo a hablar de ella, y Carlos no tiene intenciones firmes de hacerlo. En esta familia, la madre es un tema proscrito que deja un hueco en la historia familiar e individual de padre e hijo que, a su vez, es indicio de la presencia de un duelo no elaborado que los separa afectivamente. 
La partida de la madre fue fantasmatizada por Luis como prueba de una falta de amor hacia él debido a que seguramente fue un niño malo. Luis se ha identificado con esa imagen mala fantasmatizada de sí mismo. El odio dirigido hacia la madre se repartió entre su padre y él, lo cual oculta un duelo que no ha sido posible elaborar.

En cuanto al aspecto espacial, Luis es depositario de las esperanzas de Carlos. Al conformarse con no ser deportado, con ser invisible, Carlos renuncia, al menos temporalmente, a tener satisfacciones o logros propios. Está resignado a la vida que tiene, pero la perspectiva de ofrecerle a su hijo oportunidades de vida que él no tuvo ni tendrá es el aliciente que compensa la precariedad de su vida actual.

Por su parte, Luis se encuentra en el periodo de reconfigurar sus identificaciones y los modelos que su medio social le ofrecen son los de joven que se fueron "a la calle" sintiendo que no hay otro lugar para ellos "sólo saben encerrarnos o expulsarnos". Estos jóvenes se presentan como el único ideal en lo inmediato, y ser como ellos es la única manera de tener "respeto" de los demás y de uno mismo; en otras palabras, vivir y sobrevivir en las calles, con sus riesgos y peligros, es la única manera en que el yo se siente valioso.

Sin embargo, una parte de Luis sabe que esa vida no es la que él desea. Sufrir una muerte violenta o ser confinado en presión se le presentan como los dos destinos finales a los que aspiraría de irse a la calle, y eso lo hace dudar y detenerse. Además, la posibilidad de mejorar su situación económica, cambiar de escuela y de vecindario cuando Carlos compra la camioneta y las herramientas de jardinería de su patrón, y luego el riesgo de perder esa posibilidad cuando le roban todo a Carlos, hacen que Luis se una a su padre en el intento de recuperar la esperanza familiar. Esa alianza padre-hijo da pie al acercamiento afectivo entre ambos. En la búsqueda, Carlos recuerda a su hijo sus raíces mexicanas, la música y la lengua castellana.

En la conversación de Carlos y Luis se manifiestan las dificultades de ambos para elaborar el duelo. La reacción de Carlos al abandono de su mujer fue de enojo con el mundo. Ese estado afectivo lo hizo incapaz de estar disponible para su hijo a nivel afectivo, por lo que Luis no contó con su apoyo para metabolizar su propio dolor. Sólo encontró a un padre enojado, quien seguramente no quiso volver a hablar por algún tiempo de su esposa. Luis se convirtió en el depositario del enojo paterno y eso es lo que actúa en su adolescencia, pero un enojo dirigido a la pareja parental.

En este contexto, las fantasías de Luis que surgieron para dar sentido a su experiencia lo hicieron identificarse como "un fastidio", y por eso se fue su madre, porque no lo soportaba. En la adolescencia actúa como un fastidio para que los demás confirmen esta fantasía. Sentirse un fastidio tiene un costo de sufrimiento, pero evita uno mayor: el de sentir que no merece el amor de su madre aun siendo un buen hijo. Esta posibilidad, provocaría un colapso narcisista que podría hundir en la depresión a Luis (8). Cuando le pregunta a su padre "¿Por qué me trajiste al mundo?", Luis pide que el padre exprese el deseo de tenerlo, su amor a él, porque sólo de ese amor y ese deseo él puede asirse para no irse a la calle, y a partir de ahí formular sus propios deseos en la vida. La oportunidad de estar con su hijo y la deportación, obligan a Carlos a elaborar su propia pérdida y hablar de lo que pasó entre él y su esposa, su enojo y su esperanza de ofrecerle a Luis lo que él no tuvo para que su hijo fuera lo que él habría querido ser, pero no pudo: "Alguien en la vida".

\section{Conclusión}

Los conceptos de contrato narcisista y proyecto identificatorio son muy útiles para entender la situación del adolescente en su búsqueda de un lugar en la sociedad. Implica un proceso de investir el espacio social y de apropiarse de su discurso, defenderlo y actuar en concordancia con él. El punto de partida del adolescente es el discurso de su familia de origen, pero la relación que guarde con ella determinará el grado en que se mantiene fiel a él o lo rechaza en favor de otro proveniente de su medio sociocultural.

Por lo tanto, estos conceptos tienen una estrecha relación con problemas sociales. La inserción de los jóvenes en la vida social ha sido difícil en los últimos años. No hay lugares suficientes en las escuelas de educación media superior y las oportunidades de trabajo en condiciones dignas son escasas. Por ello, el interés actual en el estudio y en seguir una carrera profesional es un remanente del pasado, cuando ambas cosas aseguraban mejores condiciones de vida.

En la actualidad, los jóvenes no encuentran sentido en la escuela, porque no ven en ella ninguna utilidad para sus vidas futuras. En cambio, piensan en opciones que den frutos de manera más inmediata y segura, entre las cuales se encuentra la criminalidad. En este terreno de incertidumbre, el dinero y el poder parecen ser los únicos objetos culturales valiosos y, por ello, codiciados. La inmediatez misma es un valor actual en detrimento de la visión de futuro, la planeación y la demora de la gratificación.

El reto de las sociedades es ofrecer a los jóvenes un lugar en el que se sientan valorados y reconocidos, y tengan suficientes recursos económicos para satisfacer sus necesidades dignamente. En un plano menos concreto, necesitan sentirse parte de una cultura, no sólo regional o nacional, sino humana. $Y$ que eso por sí mismo es valioso. A final de cuentas, ellos son los herederos de las 
grandes creaciones artísticas y científicas del ser humano.

\section{Referencias}

[1]. Aulagnier P. La violencia de la interpretación. Del pictograma al enunciado. Buenos Aires, Argentina: Amorrortu; 1977.

[2]. Weitz C. Una vida mejor. Summit Entertainment; 2011.

[3]. Freud S. Introducción al narcisismo. En: Obras Completas. Buenos Aires, Argentina: Amorrortu; 1914. p. 65-98.

[4]. Lacan J. El estadío del espejo como formador de la función del yo [je] tal como se nos revela en la experiencia psicoanalítica. En: Escritos. México: Siglo XXI; 1949. p. 99-106.

[5]. Winnicott DW. La teoría de la relación entre progenitores-infante. En: Los procesos de maduración y el ambiente facilitador Estudios para una teoría del desarrollo emocional. México: Paidós; 1960. p. 47-72.

[6]. Bleichmar HB. Introducción al estudio de las perversiones. La teoría del Edipo en Freud y Lacan. Buenos Aires, Argentina: Nueva Visión; 1980.

[7]. Nicolò V. Psicoanálisis y familia. Barcelona, España: Herder; 2014. $255 \mathrm{p}$.

[8]. Bleichmar HB. La depresión: un estudio psicoanalítico. Buenos Aires, Argentina: Nueva Visión; 1976. 